Revista de la red interuniversitaria de estudios sobre las literaturas rioplatenses contemporáneas en Francia

Prodigios borgeanos: ficciones, historias, teologías

\title{
Civilizar el infinito : el milagro, la revelación y lo sublime en la obra de Jorge Luis Borges
}

Jorge Brioso

(2) OpenEdition

Journals

Edición electrónica

URL: http://journals.openedition.org/lirico/1899

DOI: $10.4000 /$ lirico.1899

ISSN: 2262-8339

Editor

Réseau interuniversitaire d'étude des littératures contemporaines du Río de la Plata

\section{Referencia electrónica}

Jorge Brioso, «

Civilizar el infinito : el milagro, la revelación y lo sublime en la obra de Jorge Luis Borges ", Cuadernos

LIRICO [En línea], 12 | 2015, Puesto en línea el 23 enero 2015, consultado el 01 mayo 2019. URL:

http://journals.openedition.org/lirico/1899; DOI : 10.4000/lirico.1899

Este documento fue generado automáticamente el 1 mayo 2019.

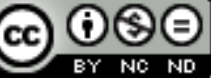

Cuadernos LIRICO está distribuido bajo una Licencia Creative Commons Atribución-NoComercial-

SinDerivar 4.0 Internacional. 


\title{
Civilizar el infinito : el milagro, la revelación y lo sublime en la obra de Jorge Luis Borges
}

\author{
Jorge Brioso
}

A Isaías Lerner,In Memoriam

\section{Introducción}

«Creo en los razonables misterios, no en los milagros brutos », (Borges 1994 :124) afirmaba Borges en un texto titulado « Elementos de Preceptiva » que apareció en Sur

el 7 de abril de 1933. Este texto resume en pocas palabras lo que podría parecer, a primera vista, el eje de la filosofía de la creación en Borges : su apuesta por el orden en contra de

la aventura

${ }^{1}$, por el régimen de representación clásico que se opone al expresivo ${ }^{2}$

, por un género como el policiaco que privilegia el rigor de la estructura narrativa y la deducción racional que se contrapone a los excesos irracionales de la vanguardia

, su apuesta, en fin, por una concepción más analítica y racional de la inspiración en contra de la clásica noción platónica que la concibe como un rapto, como un furor, como

una manía

. Pero, en una segunda mirada sobre el corpus borgiano, nos enfrentamos a dos problemas, si queremos defender la postura anterior y la noción de composición que le es inherente. 
El primero, es que en el corazón de su poética nos topamos con el más bruto de los milagros, con la más indomable de las aventuras del pensamiento. Aquel concepto que según el propio Borges : « es el corruptor y el desatinador de los otros. No hablo del mal cuyo limitado imperio es la ética, hablo del infinito" (" Avatares de la tortuga », 254). Y el primer problema lo podríamos plantear, postular como pregunta, de la siguiente manera.

¿Es posible civilizar el infinito? ¿Se puede lograr que supere su condición de bruto milagro y alcance el estatus de enigma razonado ? ¿Resulta factible integrar esa anomalía salvaje, que es cualquier infinitud, dentro de un núcleo normativo y/o representativo, de

El segundo problema tiene una doble faz. En una poética, como se supone sea la de Borges, que tiene una noción racional y metódica, léase aristotélica, del acto creativo, el concepto de revelación no debería tener un carácter protagónico. Sin embargo, en sus textos nos topamos con el concepto de revelación por todos lados. Pongo unos pocos ejemplos : la revelación de la cifra del universo en « El Aleph » y en « La escritura del Dios », la del dios único en « El acercamiento a Almotásim », la revelación estética en « La muralla y los libros », la revelación del rostro velado del profeta hereje en « El tintorero enmascarado Hákim de Merv » e incluso la de la propia infamia en « La forma de la espada ». Muy vinculado a lo anterior, pero incluso de mayor importancia, es el sesgo, el paradójico carácter que el concepto de revelación adquiere en la poética borgeana. Los dos problemas planteados son esenciales para entender el concepto de creación en Borges. El primero, el desorden que provoca el infinito en todos los sistemas clasificatorios y de ordenamiento y las posibles formas que han imaginado los hombres para tratar de narrarlo, domesticarlo, civilizarlo, constituye uno de los principales laboratorios de historias posibles para nuestro autor. Borges dedicó muchas bellas páginas a contar la biografía del infinito. La historia en la que el más veloz nunca puede alcanzar al más lento, que inmortalizó Zenón, regresa constantemente a sus páginas y constituye la matriz de inspiración de muchos de sus relatos. También aquella que resuelve la genealogía entre el padre, el hijo y el espíritu a partir de la siguiente propuesta : el padre genera eternamente al hijo y ambos, padre e hijo, al espíritu. Genealogía sin prioridad en el tiempo, sin antes ni después. Acto que nace junto con el tiempo, que crea realmente de la nada. Mucho más arduo y onmipresente en toda la obra de Borges, es otro de los retos narrativos que propone el infinito : cómo colocar en el orden sucesivo del lenguaje aquello que por naturaleza es simultáneo y que no conoce un antes y un después.

Pero también el segundo de los problemas propuestos aquí, el que nos plantea la revelación, es esencial para entender la teoría de la composición en Borges. En este caso el dilema se sitúa en cómo se relacionan en Borges el concepto de inspiración, de furor, de manía poética con el método, la reflexión racional sobre la composición de los textos ¿Se puede crear un método, una norma, una medida, un orden para el arrebato, el delirio que parece estar en el origen del acto creativo ? ¿Se pueden reconciliar a Platón y a Aristóteles? 
El trabajo, por tanto, constará de dos partes. En la primera se describe la importancia que ha tenido la secularización del estado, de la obra de arte y la inmortalidad en las principales revoluciones que ha producido el pensamiento moderno a nivel político, estético y metafísico-teológico a través de los ejemplos de Thomas Hobbes, Edgar Allan Poe y Javier Gomá Lanzón. Luego se procederá a analizar « Tlön, Uqbar, Orbius Tertius » con el objetivo de resaltar la postura crítica que la obra de Borges asume ante la tradición antes mencionada y destacar la singular dialéctica negativa que su trabajo propone para pensar la tensión entre el orden, la civilización, y el infinito.

La segunda parte del trabajo estará dedicada al estudio del concepto de revelación, de creación y de lo sublime en la obra de Borges. Aquí el problema que trataremos de analizar puede ser descrito con una pregunta : ¿en qué condiciones el universo habla mejor que el hombre?, para decirlo parafraseando al bello verso de Martí en su poema « Dos patrias ». ¿Qué escenarios crea el escritor moderno para que la palabra del universo sea escuchada? ¿Es posible, como ya se insinuó antes, una mediación entre la noción platónica del escritor poseído y que contagia a su público con su entusiasmo y el poeta dueño de un saber y conocedor de los efectos que quiere provocar en su público como es el aristotélico

? ¿Qué utilidad tiene el concepto de lo sublime para pensar la necesidad y la imposibilidad de la civilización de lo infinito ? Con este propósito, se leerán en esta parte los siguientes textos de Borges : « El acercamiento a Almotásim », « El Aleph » y « La muralla y los libros » y nos serviremos del tratado sobre lo sublime que escribió el Pseudo-Longino.

\section{Civilizar el infinito}

Para que sea posible el nacimiento del estado moderno, nos dice Hobbes, Dios tiene que

en los asuntos humanos. La fundación de la comunidad política se hace realidad en el momento en que el acceso a lo sagrado se convierte en tabú para todos los hombres a quienes solo se les permite acercarse a esa fuerza inagotable que es Dios mediante la mediación de su soberano. La definición de obra moderna que propone Poe en « The Philosophy of Composition » requiere el destierro de la inspiración y la total sacralización de los misterios ; esto convierte al autor en productor, a la obra en texto y al acto creativo en composición. La fe del sujeto moderno, según Javier Gomá Lanzón ${ }^{6}$, depende de que incluso en el más allá del estadopost mortemrijan lafinitud y la individualidad. Esta sustitución de la noción de inmortalidad por la de una mortalidad prorrogada, hecha de carne y sangre, extiende el dominio de la civilización y lo político hasta lo que hace muy poco se consideraba como el más allá o el ultramundo

. Detrás de todos estos modelos se puede detectar una especie de hiperinflación de lo civil y lo político que caracteriza al sistema de representación moderno.

El proceso que he descrito como civilización del infinito y que supone la total urbanización o politización del pensamiento cubre un amplio lapso pues nace en el siglo

XVII y llega hasta nuestros días donde termina por alcanzar una total hegemonía. El telos 
moral de lo humano. Esta noción nace de la mano de Hobbes y de su noción del Leviatán como un Dios mortal. En nuestro siglo, sobre todo en su segunda mitad, viene a ser la democracia la que viene a ocupar el lugar del mayor logro civilizatorio de la humanidad y en el mismo se piensa, se crea, se hace política, e incluso se cree en Dios bajo la convicción de que todas las esferas del hacer humano deben subordinarse a tres de los grandes pilares de la sociedad democrática : la finitud, la igualdad y el carácter construido y artificial de todo lo que hay

. A la democracia concebida como el proyecto de construir una sociedad igualitaria sobre bases finitas

se subordinan los proyectos intelectuales más influyentes de la segunda mitad del siglo $\mathrm{XX}$ : Rawls, Habermas, Rorty, entre otros

Pensar la fórmula « civilizar el infinito » desde su tensión dialéctica, como lo hace Borges, supone resistirse a los intentos de urbanizar el universo que ha realizado el pensamiento moderno. Hay que aclarar, sin embargo, que esto no conlleva que se proponga la postura contraria : la restauración total de un pensamiento extramuros y los derechos de injerencia del infinito en los asuntos de este mundo

. Lo que se propone, más bien, es seguirle el rastro a las formas en que la revelación, el milagro irrumpen desde el centro de los textos más profanos. Tratar de buscar una articulación que permita pensar la brutalidad inherente a todo milagro y el nuevo carácter razonado que han adquirido los enigmas.

La índole contrafáctica de todo milagro y su poder de contagio queda atenuada y contenida, en el mundo literario de Borges, por su carácter secreto. Secreta es la revelación, solo la conocen Carlos Argentino Daneri y Borges, del Aleph en el sótano de la casa de la calle Garay. Secreto es el milagro íntimo de Hladik en « El milagro secreto » al

que es ajeno todo el universo salvo él y el Dios que lo otorga. También permanece en secreto la sentencia mágica del Dios que descubre en su celda el mago de la pirámide de Qaholom en el cuento « La escritura del Dios » y que servirá para conjurar todos los males que se avecinan en el fin de los tiempos. Ese modo elíptico, casi íntimo, en el cual acontece el milagro en la literatura de Borges impide su intervención directa en los asuntos de este mundo. Seres derrotados son todos los destinatarios de ese don de excepcionalidad infinita lo que hace que todos los milagros terminen sepultados en el olvido. Pareciera que la brutal suspensión de los hechos, tanto los reales como los posibles, y la afirmación de una excepcionalidad irreductible a toda norma que impone todo milagro puede coexistir en paz con las leyes que rigen este universo.

En « Tlön, Uqbar, Orbis Tertius » la creación de la enciclopedia de Tlön también surge de un modo secreto, como parte de una conjura, de una conspiración. Pero resulta imposible mantener en secreto una obra de tal magnitud ${ }^{11}$ sobre todo si ha sido ideada por los hombres.Tlön, Uqbar, Orbis Tertius

( «la obra más vasta que han acometido los hombres »,OC I

: 441) es una enciclopedia donde se describe un universo inventado por una sociedad secreta de biólogos, astrónomos, metafísicos y poetas, etc. Hay que señalar, además, que para merecer tal epíteto « Obra Mayor de los hombres » ( 
OCI

: 442) esta enciclopedia que postula un universo tiene que superar en ambición, en grandeza, en desafío al orden divino, a la mítica torre que erigieron los hombres, cuando todavía hablaban un mismo lenguaje, para llegar al cielo.

Esta enciclopedia, incluso en mayor grado que los milagros descritos anteriormente, se dedica a suspender y desarreglar los órdenes que configuran el rostro reconocible del universo que los humanos consideraban, hasta ese momento, como propio. En Tlön, al sustituirse la verdad y la verosimilitud por el asombro se destituye el principio que

trataba de proponer una correspondencia entre las ficciones que produce la mente

humana y la dura prosa de la realidad. Al destituir el reinado de los sustantivos y de la ousíapor un lenguaje de verbos y de epítetos

se impugna la identidad y la esfera del nombrar que le es inherente ${ }^{12}$.

Los objetos ideales de Tlön son compuestos, hechos por diferentes sensaciones y percepciones de la realidad cuya conjunción es instantánea y contingente y que nunca

llega a reificarse o convertirse en una sustancia. « El hecho de que nadie crea en la realidad de los sustantivos hace interminable su número. Los idiomas del hemisferio boreal de Tlön poseen todos los nombres de las lenguas indoeuropeas y otros muchos más » ( OCI

: 414). Los sustantivos que permiten a cada lenguaje contabilizar y definir lo que hay son interminables en Tlön, lo que hace que su lengua tienda al infinito. También proliferan de modo infinito las teorías científicas y los sistemas filosóficos

. Hay una total conciencia en Tlön de la arbitrariedad de los sistemas que no son más que la subordinación de todos los aspectos del universo a uno cualquiera de ellos. Esta conciencia no impide, sin embargo, que la artificialidad de las leyes de ese universo ejerza una fatídica seducción sobre este mundo

14. « El contacto y el hábito de Tlön han desintegrado este mundo » (OC I

: 442). Lo conjetural termina por suplantar lo real, el pasado apócrifo, inventado, lo realmente existente. La inmunidad

15

a lo infinito que toda civilización moderna necesita para la preservación del orden que ha creado termina siendo destruida por la capacidad de contagio que tiene la intrusión del mundo fantástico en el real, por el estado de excepción que supone la irrupción del milagro en este mundo.

Pero la paulatina desaparición de este mundo no solo se debe al contacto y al hábito de Tlön ; como se dijo anteriormente, la propia realidad colaborará, y de modo activo, en este proceso. La realidad, nos aclara Borges,

[...] anhelaba ceder. Hace diez años bastaba cualquier simetría con apariencia de orden -el materialismo dialéctico, el antisemitismo, el nazismo- para embelesar a los hombres. ¿Cómo no someterse a Tlön, a la minuciosa y vasta evidencia de un planeta ordenado ? Inútil responder que la realidad también está ordenada. Quizá lo esté, pero de acuerdo a leyes divinas -traduzco : a leyes inhumanas- que no acabamos nunca de percibir. Tlön será un laberinto, pero es un laberinto urdido por hombres, un laberinto destinado a que lo descifren los hombres. (

OC I :442) 
« Tlön, Uqbar, Orbis Tertius » es el texto esencial para entender la crítica que propone Borges a la lectura política del universo. Tlön es una parábola antipolítica

ya que se erige como una alerta contra la tendencia moderna a politizar lo real y a convertir ese momento político en uno de los aspectos centrales de toda forma, de toda organización del sentido. Esta tradición se funda en la siguiente premisa de la que « Tlön... » dibuja su parodia : transformar cualquier simetría en orden y cualquier orden en una fórmula para organizar la convivencia pasada, presente o futura de los hombres. Hay algo inhumano, salvaje, intraducible en términos civilizatorios, en las leyes que rigen el universo real. El infinito nunca se deja civilizar totalmente. Para Borges, el infinito es la

barbarie

. No se debe olvidar, sin embargo, que es el propio Borges el que sugiere que los principales horrores en el mundo moderno se han hecho en nombre del orden, de la civilización.

\title{
La sintaxis del milagro : la búsqueda de una prosodia para lo sublime
}

\author{
Infinity fills the mind with that sort of delightful \\ horror which is the truest test of the sublime ; and \\ succession and uniformity of parts, which \\ constitute the artificial infinite, give the effect of \\ sublimity in architecture [...]. No work of art can \\ be great but as it deceives. (Burke. \\ A Philosophical Enquiry into the Origin of Our Ideas of \\ the Sublime and Beautiful
}

En esta parte del trabajo nos dedicaremos a explorar si es posible superar elimpasse

que habíamos detectado entre las leyes del universo y la civilización a partir de la categoría de lo sublime. ¿Es posible hallar una mediación entre lo sublime, que se asocia en su acepción moderna a una grandeza inconmensurable y a la radical otredad de una naturaleza no sometida al hombre, y el orden con límites definidos y acotables y de carácter ficcional que propone la obra de arte ? Si el rapto que provoca la visión de lo infinito puede ser convertido en una vivencia estética, ¿puede haber entonces una mediación entre la forma y lo inconmesurable ? ¿O tiene toda teoría sobre lo sublime que terminar, como ha sido el caso en gran parte del pensamiento estético post-kantiano sobre este concepto, en una celebración de lo informe? ¿Pueden ser reconciliables el método y el rapto, el acto creador y la composición? ¿De qué forma irrumpe la revelación de lo divino o de la infinitud inherente al universo dentro de los textos de Borges? ¿Qué escenarios crean los textos de Borges para que la palabra del universo sea escuchada?

Para tratar de responder a algunas de estas preguntas acudiré a uno de los primeros cuentos de Borges, "El acercamiento a Almotásim" publicado primero en su Historia de la eternidaden 1936 e incluido luego en la edición deFicciones 
en 1944. «Su protagonista », nos dice Borges respecto a este cuento que tiene, como muchos suyos, la forma de una reseña de una novela apócrifa, « es un estudiante de derecho en Bombay. Blasfematoriamente, descree de la fe islámica de sus padres, pero al declinar la décima noche de la luna de muharrán, se halla en el centro de un tumulto civil entre musulmanes e hindúes » (

OCI

: 414-415). Es en ese tumulto donde cree haber matado a un idólatra, a un hindú, sin ser capaz de saber si su Dios único es mejor que el dios múltiple. Mientras huye es que se produce su contacto con la revelación. La revelación le llega a través de la infamia de un hombre profanador de cadáveres, uno de esos tantos héroes borgianos que fatigan la infamia, y de su lengua vulgar y soez. Los nombres alrededor del cual este hombre abyecto y vil concentra su desprecio se le quedan grabados en la memoria al joven musulmán ; sobre todo : « el de la mujer malka sansi (mujer de casta de ladrones)[...] muy preferida por las imprecaciones y el odio del despojador de cadáveres. [El protagonista de nuestra historia] [a]rguye que el rencor de un hombre minuciosamente vil importa un elogio» ( OCI

: 415). Detrás del rencor y de la blasfemia se debe encontrar algo admirable y digno de afecto. La revelación se inscribe como un negativo en el dorso de la palabra abyecta y del encono. La novela luego se dedicará a narrar las aventuras que vive este joven mientras sigue las huellas que lo divino ha dejado en múltiples almas y que él sintió que se le revelaba por primera vez a través del más vulgar de los injuriadores. No se debe olvidar Historia de la Eternidad que « El acercamiento a Almotásim » aparece en un apéndice de y que lleva como título : « Dos notas ». La otra nota que aparece en este apéndice es « El arte de injuriar ». Como sugiere mi lectura, ambos textos deberían leerse en conjunto. La persecución de las huellas de lo divino, su canto y celebración, son inconcebibles sin el arte de la injuria. La celebración en Borges adquiere siempre la forma de la vindicación. Sólo se puede celebrar aquello que previamente se ha injuriado.

Borges al principio de « El acercamiento a Almotásim » insiste en que esta supuesta novela se estructura a partir del « mecanismo policial de la obra y su undercurrentmístico » (OC I :

414). Podía y debía haber dicho también que hay un secreto hilo en esta historia, como en todas las suyas, entre la abyección y el anhelo de infinito, que sus historias se hacen de infamia y de eternidad. Una de las constantes de Borges, quizás la clave de su proyecto estético, es ese contrapunto constante entre lo sublime y lo infame o vil, entre lo eterno y lo abyecto, vulgar o nimio. Este contrapunto soluciona, creo, la dicotomía entre el Borges metafísico y el Borges criollo y arrabalero. Este contrapunto, además, aporta una genealogía para el concepto de ficción, y por extensión de composición en Borges. Se podría decir que las dos nociones más importantes de su obra se gestan en dos de los mejores libros que Borges escribió en los años treinta : el infinito en Historia de la Eternidad, la infamia, lo vil, lo abyecto enHistoria Universal de la infamia.

El cuento « El Aleph » publicado en 1949 en el libro que lleva el mismo título reúne muchos de los temas que he venido tratando. Vale la pena entonces que nos detengamos en él. Borges concibe el enigma - sigue en esto a Aristóteles - como una conmensura de 
. El enigma se constituye al poner juntas dos cosas : un libro y un laberinto (como en « El jardín de los senderos que se bifurcan »), dos actos : la quema de todos los libros y la construcción de la gran muralla (como en « La muralla y los libros »), dos personas : el traidor y el héroe (como en « El tema del traidor y del héroe »), que se consideran incompatibles entre sí. «El Aleph » propone otra de estas enigmáticas conjunciones y nos trae juntos al más prolijo, mediocre y cacofónico de todos los poetas, Carlos Argentino Daneri, y al Borges ficticio más inspirado y rapsódico. No está de más recordar que la primera vez que aparece la palabra enigma en Occidente es en

La Teogoníade Hesíodo ${ }^{19}$

. Allí se nos cuenta la historia de dos adivinos que disputan por un misterio cuyo contenido es banal. El enigma se estructura entonces no tanto por la trascendencia del misterio como por el agón

, la lucha, de dos adivinos por la sabiduría, por el conocimiento. En «El Aleph » el contenido del enigma está muy lejos de ser banal, se trata nada más y nada menos que de la cifra del universo, pero lo que se deriva de ese descubrimiento, lo que el enigma termina por revelar, sí parece serlo. El

agón

, la lucha por la fuente de inspiración, por la poesía, por Beatriz Viterbo, permea, sin duda, todos los recovecos de esta historia.

El vínculo entre estos dos hombres antitéticos es Beatriz Viterbo, prima hermana de

. La historia comienza el día de la muerte de Beatriz y nos narra los esfuerzos de Borges, ante un universo que cambia incesantemente, que se aleja y la olvida, por mantener intacta la memoria de su amada. El cuento nos narra la historia de un largo proceso de duelo

que dura catorce años y en el que termina, como casi siempre sucede en estos casos, venciendo el olvido.

En el transcurso de estos años Borges regresa puntualmente a casa de Beatriz cada día de su cumpleaños. Pero no es hasta el año de 1941, doce años después de haber sido iniciadas estas visitas, cuando Carlos Argentino Daneri le habla a Borges de su poema « La Tierra » que describe en los siguientes términos : « tratábase de una descripción del planeta ${ }^{22}$, en la que no faltaban, por cierto, la pintoresca digresión y el gallardo apóstrofe » (OC I :

619). Pero es este poema que según el narrador « parecía dilatar hasta el infinito las posibilidades de la cacofonía y el caos » (

OC I :

622) el que conecta a los lectores y al Borges protagonista de esta historia con el Aleph. Carlos Argentino Daneri le confiesa a Borges, aterrorizado por la posibilidad de la demolición de su casa, que este poema es fruto de su visión del Aleph que define como : « el lugar donde están sin confundirse, todos los lugares del orbe, vistos desde todos los

OC I :623). El más horrible de los poemas,La tierra

ángulos » (

de Carlos Argentino Daneri, la más horrenda de las obras literarias, es fruto de la más sublime y sagrada de las visiones. 
Pero el lector no se va a quedar sólo con la falsa y distorsionada visión del objeto sagrado, también el Borges ficticio del relato nos va a ofrecer su visión de este maravilloso objeto.

Para proponerle una sintaxis al infinito, Borges nos regalará la más larga oración y cadena de imágenes, visiones, que jamás producirá su literatura. Esta oración, casi infinita ella misma, oración letanía, oración mantra, nos ofrece 34 visiones, instantáneas

fotográficas, para describir el universo : «Vi el populoso mar, vi el alba y la tarde, vi las

\section{OC I :625). La repetición ${ }^{23}$}

muchedumbres de América [...]»(

del verbo « vi » 34 veces y la belleza de muchas de sus imágenes le otorga un carácter mágico, casi místico, a este texto. Poco de método y mucho de rapto parece haber en el mismo. La piedra magnética del Aleph, para usar la bella imagen del diálogo platónico Ion

, parece haber contagiado con su fuerza al Borges-poeta de esta historia y al lector de la misma. La cadena de entusiasmos que describía Platón entre la inspiración, el poeta y su público parece cumplirse cabalmente.

Sin embargo, el Borges-poeta de esta historia, a diferencia de los poetas que describe Platón en sus diálogos, no sólo es capaz de poseer su objeto sino que también puede dar cuenta de él. La elección del tipo de prosodia necesaria para contar y cantar el infinito, aunque sea de un modo limitado y precario, forma parte de una decisión consciente del escritor. Dice este un momento antes de emprender su oración-letanía :

¿cómo transmitir a los otros el infinito Aleph, que mi temerosa memoria apenas abarca ? Los místicos, en análogo trance prodigan los emblemas : para significar la divinidad, un persa habla de un pájaro que de algún modo es todos los pájaros ; Alanus de Insulis, de una esfera cuyo centro está en todas partes y la circunferencia en ninguna ; Ezequiel, de un ángel de cuatro caras que a un tiempo se dirige al Oriente y al Occidente, al Norte y al Sur. [...] Quizá los dioses no me negarían el hallazgo de una imagen equivalente, pero este informe quedaría contaminado de

literatura, de falsedad. Por lo demás, el problema central es irresoluble : La enumeración, siquiera parcial, de un conjunto infinito [...] Lo que vieron mis ojos fue simultáneo : lo que transcribiré sucesivo, porque el lenguaje lo es. Algo, sin

OC I :625) embargo, recogeré. (

Y algo, sin duda, recoge. Ya dijimos que la oración en que describe el Aleph probablemente sea uno de los momentos más logrados e inspirados de la poesía borgiana. Parece, entonces, que puede haber un camino intermedio entre el poeta poseído de Platón y el poeta calculador de Aristóteles. Existe al menos una fuente clásica que antecedió a Borges en este cometido : el tratado sobre lo sublime del Pseudo-Longino. El anónimo autor de este breve tratado de retórica afirma :

La grandeza, dicen, es congénita y no sobreviene con la enseñanza. La única técnica para llegar a ella es por actitud natural. Las obras de la naturaleza, según piensan ellos, se echan a perder y se las envilecen totalmente cuando se las somete a las reglas del arte, reduciéndolas a su esqueleto. Yo, en cambio, afirmo que se puede probar lo contrario, si se considera que, mientras la naturaleza por lo general se muestra autónoma en los estados emocionales y exaltados, sin embargo, no tiende a ser azarosa ni por completo falta de método. Ella misma es el principio originario y arquetípico que sostiene toda producción, pero sólo el método es capaz de delimitar y proporcionar la medida, el momento preciso para cada caso concreto, e incluso la práctica y el uso más seguros. Los grandes genios están más expuestos al peligro cuando, abandonados a sí mismos, sin ciencia, sin ancla y sin lastre, se dejan llevar por el sólo ímpetu y la ignorante temeridad : ellos necesitan a menudo de espuelas y también de freno. $(2007: 22)$ 
El rapto tiene un valor normativo. El método nace a partir de él. La exaltación de la naturaleza, su expresión de autonomía, no supone, como pensaban los románticos, una suspensión de las normas, del orden, de la medida. Más bien todo lo contrario, la

arché

de toda norma. Esto supone que el umbral de la civilización tenga que abrir sus puertas a lo ilimitado, a lo inconmensurable. Va a ser entonces lo inconmensurable y lo ilimitado lo que estará en el origen de la medida y la forma. La fórmula correcta no sería entonces la civilización del infinito sino la infinitud de la civilización. Nadie lo ha expresado mejor que Baldine Saint Girons en su excelente estudio

Lo sublime

: «Si de verdad, como pretendía Longino, se da una educación por lo sublime, esta educación es muy diferente del mero aprendizaje técnico y conlleva el fenómeno central

(pero siempre inquietante, en cuanto imprevisible) de la inspiración » (2008: 87). Muy importante, además, es la distribución de los roles que establece el Pseudo-Longino entre

la naturaleza y el arte. La naturaleza aporta la buena fortuna y el arte la ocasión, la facultad de decidir bien. Pero lo que es más importante, “es sólo el arte que nos puede enseñar que ciertos rasgos de la literatura dependen únicamente de la disposición natural » (2007 : 23). Es decir, que la naturaleza a la cual se accede aquí es una naturaleza que tiene que atravesar por la educación, por el momento civilizatorio, por la techné

. Se postula la infinitud de la civilización pero sin restaurar, como ya se ha alertado varias veces en este artículo, la injerencia directa del infinito en la civilización.

Ya es hora que regresemos, entonces, al canto-salmo que había colmado tanto al Borgespoeta de la historia como a nosotros los lectores, de entusiasmo. Más que referirse a la plenitud, la gran revelación que el universo le tenía reservado a Borges habla el lenguaje de la traición, de la caducidad, de la muerte. Esta revelación múltiple del universo contiene el más cruel de los desengaños, la más desencantada de las visiones : « [...] vi en un cajón del escritorio (y la letra me hizo temblar) cartas obscenas, increíbles, precisas, que Beatriz había dirigido a Carlos Argentino, [...] vi la reliquia atroz de lo que

$O C I$

: 625). Las cartas que desenmascaran la relación incestuosa entre Beatriz Viterbo y su primo hermano y la visión del cadáver, la calavera de Beatriz, rompen el encanto místico de este salmo. La verdad que revela el enigma, el secreto, como en muchas historias de

Borges, es a la vez atroz y banal. Es la visión de la más infame de las traiciones y de la vanitas

, la calavera de la amada, la que provoca la disolución del recuerdo de Beatriz Viterbo en la mente de Borges y el fin de este cuento. 
Ya hemos visto cómo de la injuria se pasa a la persecución y la búsqueda de lo sagrado y cómo se relacionan la revelación de la cifra del universo con la creación poética, el rapto de la inspiración y el método creativo. Nos falta indagar ahora cómo Borges concibe la revelación estética. En la revelación estética también aprenderemos varios elementos esenciales para la mejor comprensión de la noción de composición en Borges. ¿Qué importancia tienen las emociones y los afectos en la creación? ¿Qué rol ocupa la forma y la sensibilidad en el acto creativo ? ¿Cuál es el peculiar sesgo que le da el hecho estético a la revelación? Con este objetivo leeremos, y con esto concluimos, su bello ensayo « La

Otras Inquisicionesde 1952. muralla y los libros » incluido en

En « La muralla y los libros ${ }^{24}$

", el texto que nos interesa ahora, lo primero que se nos dice es que se quiere descubrir las razones de la emoción que provoca en el escritor la noticia de que el mismo emperador que dispuso la quema de todos los libros fue aquel que ordenó la creación de la muralla china. Una emoción hecha por la satisfacción y la inquietud. Un cierto placer que acompaña un cierto desasosiego. Se debe recordar que en el caso de Borges el resorte narrativo es siempre un afecto. Siempre la máquina de razonar se activa para tratar de dilucidar un afecto o una emoción : el duelo por la amada muerta en « El Aleph », el odio en « El hombre de la esquina rosada », la venganza en « La muerte y la brújula » y un largo etcétera. Borges nos aclara, al principio del texto, que el misterio no es histórico ya que se saben los hechos que explican el contexto en el que se produjeron estos dos actos que desafían la imaginación humana. Los hechos en sí mismos tampoco son inverosímiles : quemar libros y aislar reinos son actos que repiten todos los príncipes despóticos. Lo que los hace diferentes es su escala, su magnitud : quemar todos los libros, construir una muralla que aísle a China de todo el mundo. Lo que preocupa no es tanto un

hecho sino su cualidad, su dimensión. Es esta dimensión lo que hace que el hecho sea inexplicable, inimaginable. Es una cualidad que más que acercar el hecho a su esencia, a su género, lo separa, lo convierte en una anomalía. 
Lo realmente original es la insistencia de Borges en que este afecto se dispara por la magnitud, la inmensidad, del dato que le provee la realidad. Esta cualidad (la inmensidad)

le otorga cierta irrealidad al dato, cierta anomalía que no se deja domesticar por explicaciones históricas, políticas, filosóficas, ni siquiera por la indignación que pueda provocar el drama humano que este dato porta : la destrucción de los libros (que para alguien que concibió el paraíso como una biblioteca es, sin duda, el más infame de los actos), el castigo y tortura de los que trataron de preservarlos, el trabajo esclavo que construyó la absurda muralla. La proporción de los hechos narrados no permite que nos reconozcamos en ellos : no hay anagnórisis, ni hacemos catarsis al ver tanto dolor. La emoción tiene otro carácter. Esto no la convierte en deshumanizada - aquí se equivocó la vanguardia -, sino que más bien le otorga otra humanidad. Se trata de indagar, y para esto solo sirven las conjeturas, esa secreta relación que el afecto guarda con esa cualidad.

Las conjeturas entonces postularán mundos posibles donde la enigmática historia del afecto y la cualidad pueden tener lugar. No se debe olvidar que la intensidad de la cualidad a la que nos referimos separó a este hecho histórico de todos los otros, lo hizo ininteligible, radicalmente singular. Esta singularidad es la que provoca admiración y estupor. Las conjeturas, más que explicar o justificar o describir (en lugar de preguntar

sobre el qué, el por qué, el para qué, el cómo) proponen mundos posibles donde la cualidad y su afecto puedan habitar. A cada posible respuesta le antecede un quizás, un tal vez, un acaso, locuciones que designan estos mundos hipotéticos. Este intento, el de las conjeturas, termina en aporía. Llega a un punto ciego. Borges dice explícitamente que fracasa, pero nos revela la forma desnuda, nos obliga a vivir la experiencia de la forma. La cualidad persiste (la inmensidad) pero sin su sustancia. El adjetivo sobrevive al sustantivo. Los acontecimientos (la destrucción y la construcción) sobreviven pero sin los sujetos que los realizaron y los objetos que los sufrieron. Al menos, en otras tres ocasiones, en « Tlön, Uqbar, Orbius Tertius », en « Funes el memorioso » y en « El inmortal ", había postulado Borges la ficción de un lenguaje sin sustantivos y sin sujetos. Se nos pide que abandonemos todas las escalas con que hacemos inteligible la realidad, que suele definirse a través de la ousía

, de la sustancia, de la identidad. Se nos pide que nos atrevamos a pensar las formas desnudas : los adjetivos y los verbos del lenguaje. No lo sustantivo sino lo adjetivo y su devenir 25

. Es a través de este lenguaje virtual que el texto estético trata de construirle una prosodia al infinito, una sintaxis. Es a través de este lenguaje posible que el texto estético nos propone su concepto de revelación : « La música, los estados de felicidad, la mitología, las caras trabajadas por el tiempo, ciertos crepúsculos y ciertos lugares, quieren decirnos algo, o algo dijeron que no hubiéramos debido perder, esta inminencia de una revelación, que no se produce, es quizá, el hecho estético » ( OC II :13). 


\section{BIBLIOGRAFÍA}

Aristóteles.Poética.Madrid: Gredos, 1992.

Badiou, Alain.Lógicas de los mundos.El ser y el aconteciento, 2.Buenos : Manantial, 2008.

Berlin, Isaiah.Two Concepts of Liberty. Oxford : Clarendon Press, 1959.

Borges, Jorge Luis. "Avatares de la tortuga".Obras completas. vol. 1

. Buenos Aires : Emecé, 2002. 254-259.

Borges, Jorge Luis. « El Aleph ».Obras completas. vol. 1.Buenos Aires : Emecé, 2002. 617-629.

Borges, Jorge Luis. «El acercamiento a Almotásim ».Obras completas. vol. 1.

Buenos Aires : Emecé, 2002.414-418.

Borges, Jorge Luis. «El cuento policial ».Obras completas

. vol. 4. Buenos Aires : Emecé, 2002. 189-198.

Borges, Jorge Luis. « Elementos de preceptiva ».Jorge Luis Borges en Sur, 1931-1980

. Buenos Aires : Emecé, 1999. 121-126.

Borges, Jorge Luis. « El inmortal ».Obras completas. vol. 1.Buenos Aires : Emecé, 2002. 533-545.

Borges, Jorge Luis. « El milagro secreto ».Obras completas. vol. 1.

Buenos Aires : Emecé, 2002. 508-514.

Borges, Jorge Luis.El tamaño de mi esperanza. 5th ed. Madrid : Alianza Editorial, 2008.

Borges, Jorge Luis. « El tintorero enmascarado Hákim de Merv ».Obras completas. vol. 1

. Buenos Aires : Emecé, 2002. 324-329.

Borges, Jorge Luis. «Funes el memorioso ».Obras completas. vol. 1.

Buenos Aires : Emecé, 2002. 485-491.

Borges, Jorge Luis. « La escritura del Dios ».Obras completas. vol. 1.

Buenos Aires : Emecé, 2002. 597-600.

Borges, Jorge Luis. «La génesis de ‘El cuervo' de Poe ».Textos recobrados 1931-1955

. Barcelona : Debolsillo, 2011. 118-122.

Borges, Jorge Luis. « La muralla y los libros ».Obras completas. vol. 2.

Buenos Aires : Emecé, 2002. 11-14.

Borges, Jorge Luis. « Tlön, Uqbar, Orbis Tertius ».Obras completas. vol. 1.

Buenos Aires : Emecé, 2002. 431-444.

Bréhier, Emile.La Théorie des incorporels dans l'ancien stoïcisme. Paris : Librarie Alph onse Picard \& Fils, 1908.

Colá, Santiago. « Hopelessness and Potency : Borges' "El Aleph" ».Web. 15 de octubre de 2014.

Colli, Giorgio.La sabiduría griega. Diónisos Apolo Eleusis Orfeo Museo Hiperbóreos Enigma

. 2nd ed. vol. 1.Valladolid : Editorial Trotta, 1998.

Dabove, Juan Pablo, ed.Jorge Luis Borges : Políticas de la Literatura

. Pittsburgh : Instituto Internacional de Literatura Iberoamericana, 2008. 
Deleuze, Gilles.Lógica del sentido. Buenos Aires : Paidós, 2005.

Díaz, Hernán.Borges, Between History and Eternity. London : Continuum, 2012.

Esposito, Roberto.Bios : Biopolitics and Philosophy

. Minneapolis : University of Minneapolis Press, 2008.

Giordano, Alberto.Modos del ensayo :Jorge Luis Borges-Oscar Masotta

. Rosario : Beatriz Viterbo Editora, 1991.

Gomá Lanzón, Javier.Ejemplaridad Pública. Madrid : Taurus, 2009.

Gomá Lanzón, Javier.Necesario pero imposible O ¿Qué podemos esperar ?Madrid : Taurus, 2013.

Hobbes, Thomas.Leviathan.The Claredo Edition of the Works of Thomas Hobbes

. Vol 2-3. Oxford : Oxford University Press, 2012.

Pauls, Alan.El factor Borges.Barcelona : Anagrama, 2004..

Poe, Edgar Allan.Essays and Reviews. New York, NY : Literary Classics of the U.S.,1984.

Pseudo-Longino.De lo sublime. Chile : Metales Pesados, 2007.

Rodríguez, Fermín. « Saber dar muerte : El arte del duelo en Jorge Luis Borges ».

Latin American Literary Review.36.71 (2008) : 99-131.

Ruiz, Pablo Martín.

Four Cold Chapters on the Possibility of Literature : Leading Mostly to Borges and Oulipo

. Champaign : Dalkey Archive, 2014.

Santí, Enrico Mario.Ciphers of History : Latin American Readings for a Cultural Age.

New York : Palgrave Macmillan, 2005.

Saint Girons, Baldine.Lo sublime. Madrid : Antonio Machado Libros, 2008.

Zellini, Paolo.Breve historia del infinito.Madrid : Ediciones Siruela, 2004.

\section{NOTAS}

1.

Esta distinción, central para su poética, aparece por primera vez en « La aventura y el orden » pequeño ensayo incluido en El tamaño de mi esperanza

. Borges recupera esta distinción de Apollinaire que « separa a los escritores en los estudiosos del Orden y los traviesos de la Aventura » (2008: 75).

2.

La postulación clásica de la realidad, que aparece en la obra de Borges bajo diferentes denominaciones, no solo se opone a lo expresivo. En

Evaristo Carriego 
(1930), por ejemplo, la distinción se establece entre lo que Borges llama el estilo del recuerdo que asocia a su literatura y el copioso estilo de la realidad que vincula a la novela, género siempre denostado por Borges : « Este, pues, Domínguez Palermo, proveedor de carne de la ciudad entre los años 1605 y 14, poseía un corral cerca del Maldonado, destinado al encierro o la matanza de hacienda cimarrona. Degollada y borrada ha sido esa hacienda, pero nos queda la precisa mención de una mula tordilla que anda en la chácara de Palermo, término de esta ciudad. La veo absurdamente clara y chiquita, en el fondo del tiempo, y no quiero sumarle detalles. Bástenos verla sola : el entreverado estilo incesante de la realidad, con su puntuación de ironías, de sorpresas, de previsiones extrañas como las sorpresas, sólo es recuperable por la novela, intempestiva aquí. Afortunadamente, el copioso estilo de la realidad no es el único : hay el del recuerdo también, cuya esencia no es la ramificación de los hechos, sino la perduración de rasgos aislados. Esa poesía es la natural de nuestra ignorancia y no buscaré otra » (105). En « La postulación de la realidad » ensayo aparecido en Discusión

(1932) y donde los términos que se oponen son el expresivo y el clásico se afirma lo siguiente : «Yo aconsejaría esta hipótesis : la imprecisión es tolerable o verosímil en la literatura, porque a ella propendemos siempre en la realidad. La simplificación conceptual de estados complejos es muchas veces una operación instantánea. El hecho mismo de percibir, de atender, es de orden selectivo : toda atención, toda fijación de nuestra conciencia, comporta una deliberada omisión de lo no interesante. Vemos y oímos a través de recuerdos, de temores, de previsiones. En lo corporal, la inconsciencia es una necesidad de los actos físicos. Nuestro cuerpo sabe articular este difícil párrafo, sabe tratar con escaleras, con nudos, con pasos a nivel, con ciudades, con ríos correntosos, con perros, sabe atravesar una calle sin que nos aniquile el tránsito, sabe engendrar, sabe respirar, sabe dormir, sabe tal vez matar : nuestro cuerpo, no nuestra inteligencia. Nuestro vivir es una serie de adaptaciones, vale decir, una educación del olvido » (218). Estilo del

recuerdo, educación del olvido son dos formas de designar un ejercicio con el lenguaje que la obra de Borges va a proponer para tratar de acotar la copiosa minuciosidad de lo real. Su escritura, sin embargo, no se conforma con mantenerse dentro del coto vedado que le regala la pedagogía del olvido. Las incursiones al infinito territorio de lo real son parte esencial de muchos de sus mejores textos.

3.

Múltiples son las declaraciones de Borges de este tenor. La más clara y rotunda es quizás la que aparece en una conferencia que dio en la Universidad de Belgrano el 16 de junio de 1978 y que

lleva por título « El cuento policial ». Allí afirma : « ¿Qué podríamos decir como apología del género policial ? Hay una que es muy evidente y cierta : nuestra literatura tiende a lo caótico. Se tiende al verso libre porque es más fácil que el verso regular ; la verdad es que es muy difícil. Se

tiende a suprimir personajes, los argumentos, todo es muy vago. En esta época nuestra, tan caótica, hay algo que, humildemente, ha mantenido las virtudes clásicas : el cuento policial sin principio, sin medio y sin fin.[...]. Yo diría, para defender la novela policial, que no necesita defensa ; leída con cierto desdén ahora, está salvando el orden en una época de desorden [...] "

(198). Acepto esta definición, "salvar el orden en una época de desorden », con la siguiente corrección : la única manera de salvar el orden en una época de desorden es inventándole una lógica al desorden, al caos. Y para Borges el archédel desorden y el caos es el infinito; esa categoría que arruina y destruye todas las otras. 
4.

Este procedimiento hace su entrada en la literatura moderna con Edgar Allan Poe. Sobre la transformación que realiza Poe en la noción de acto creativo en su clásico texto « The Philosophy of Composition » dice Borges : « ¡Del interlocutor de las musas, del poeta amanuense de un dios oscuro, pasar al mero devanador de razones! La lucidez en lugar de la inspiración, la inteligencia comprensible y no el genio, ¡qué desencanto para los contemporáneos de Hugo y aun para los de Bretón y Dalí ! » (« La génesis de "El cuervo" de Poe», 118-119).

5. A pesar de que esta figura del escritor nace con laPoética de Aristóteles, no es hasta la publicación de « The Philosophy of Composition » de Edgar Allan Poe donde los tres principios que rigen esta figura del escritor y la noción del ejercicio creativo que le es inherente (negación de la inspiración, la obra literaria concebida como la búsqueda de un efecto, carácter racional y metódico del proceso creativo) aparecen juntos y expresados con total claridad.

« Nothing is more clear than that every plot, worth the name, must be elaborated to its dénouement

before anything be attempted with the pen [...]. I prefer commencing with the consideration of

effect

[...] Most writers - poets in especial - prefer having it understood that they compose by a species of fine frenzy - an ecstatic intuition - and would positively shudder at letting the public take a peep behind the scenes, at the elaborate and vacillating crudities of thought.[...]

»(13-14).

El mejor estudio sobre esta tradición que conozco es el que realiza Pablo M. Ruiz en su libro Four Cold Chapters on the Possibility of Literature : leading mostly to Borges and Oulipo(2014).

Para la influencia de Poe en la obra de Borges ver tambiénHistory and Eternity de Hernán Díaz (2012).

6.

No trato de « ejercer el caos », como aquella Enciclopedia china que Borges inmortalizara, al yuxtaponer dos autores como Thomas Hobbes y Edgar Allan Poe, canónicos si los hay, con la obra

de un autor contemporáneo como Javier Gomá Lanzón, todavía poco conocido fuera de las fronteras de su país. Las razones que me mueven a proponer al filósofo español como uno de los hitos en los que se articula el concepto que rige mi trabajo, la civilización del infinito, son tres. Javier Gomá Lanzón en su libro

Necesario pero imposiblees el que acuña el concepto decivilizarel infinito

. Reconozco, sin embargo, que yo en este trabajo convierto en síntoma de una época a lo que fue concebido como una nueva forma de imaginar la esperanza en una vida más allá de la muerte capaz de ajustarse a las bases igualitarias y finitas de las sociedades democráticas. En mi opinión, Gomá Lanzón pertenece al paradigma de pensamiento que pretende urbanizar y politizar lo real : destituir y traducir las leyes del universo en términos finitos y humanos. Como se notará, a través de este ensayo, me distancio de esta tradición, a través de mi lectura de Borges, en varios puntos esenciales. La segunda razón que me mueve a incluir este autor tiene que ver con la originalidad y radicalidad filosófica y teológica que tiene su concepto de mortalidad prorrogada donde se sobrevive a la muerte pero sin renunciar al rasgo que ha sido sustancial para la configuración de nuestra individualidad : la finitud. Esta extensión del reino de lo político más allá de las fronteras de la propia muerte me parece un hito dentro de la narrativa que me propongo desarrollar aquí y que trata de describir las siluetas de una época con el objetivo de poder subrayar la singularidad que tiene la obra de Borges dentro de la misma. El carácter contemporáneo de la obra de Gomá Lanzón me permite extender mi argumento a la actualidad, y esta es la última de mis razones, donde la civilización del infinito con la consecuente politización de todas las esferas discursivas que le es inherente ha llegado a ser hegemónica. 
7. «[...]yerra la tradición filosófica y teológica cuando concibe la mentada supervivenciapost-mortem como una inmortalización, divinización o eternización del yo , esto es, como una mutación esencial de su verdadera y auténtica naturaleza finita » (Necesario pero imposible233).

8.

No incluyo al cuarto de estos pilares, la libertad, debido a la escisión que sobre este principio existe dentro de la propia tradición del pensamiento democrático. La libertad se puede entender tanto en un sentido positivo y negativo, para seguir la clásica distinción de Isaiah Berlin. Los que defienden la noción positiva de la libertad se preguntan sobre el sujeto del poder público : quién debe ejercer el mando y de dónde deriva esta forma de gobierno su autoridad. Los que defienden la libertad negativa indagan sobre los límites que debe tener todo poder, la libertad es entendida en esta tradición como un espacio en el que los seres humanos pueden actuar sin la interferencia de un poder externo.

9.

Tomo esta expresión de Gomá Lanzón que es el pensador que con mayor claridad y de una forma más rotunda ha convertido a la democracia en el lugar donde se encuentran por primera vez los dos rasgos principales del espíritu moderno : la finitud y la igualdad. En

Ejemplaridad pública

Javier Gomá afirma : « Así como la onto-teología y el aristocratismo formaron durante siglos una aleación casi indestructible, como dos siameses inseparables, ahora finitud e igualdad acuerdan una nueva alianza de fabulosas consecuencias, pues del beso de ambas ha nacido la democracia, entendida aquí precisamente como el ensayo colectivo de una civilización igualitaria sobre bases

finitas, un experimento histórico y sin precedentes que la humanidad está realizando en la actualidad, en medio de grandes incertidumbres, sin modelos en el pasado que le sirvan de guía » Ejemplaridad pública16).

10.

Es necesario señalar, por tanto, que también tomo distancia respecto al pensador que creo inaugura un nuevo paradigma de conocimiento en la tradición occidental respecto del rol que

tiene el infinito en el pensamiento, en lo estético, en lo político e incluso en la esfera de los afectos, el amor. Me refiero, por supuesto, a Alain Badiou. No puedo detenerme aquí a desarrollar mis diferencias teóricas con Alain Badiou. Baste decir, por ahora, que su noción de una verdad infinita que solo se entiende como excepción y sustracción de los órdenes establecidos termina convirtiendo al infinito inherente al acontecimiento-verdad en una fuerza contrafactual de tal magnitud que acaba por negar grandes sectores de la experiencia histórica del siglo XX. Para

Badiou una verdad infinita es una excepción contrafáctica que se afirma contra lo que hay, entendido esta última categoría (lo que hay) como los confines que definen el sentido de este mundo finito. Esta noción extramuros de la verdad y la total restauración del principio de acción directa de lo infinito en este mundo constituyen los dos grandes puntos en que mi postura, vía mi lectura de Borges, se separa de Badiou.

11.

La discreción respecto de los milagros pareciera ser solo potestad divina como se puede notar por los ejemplos que cité anteriormente : « El Aleph », « La escritura del Dios », « El milagro secreto ». 12.

Es con los estoicos con quien nace esta noción del lenguaje y de la realidad. Las cosas, según esta noción, más que tener un serestable o fijo se articulan en diferentes modos o maneras de ser.VerLa Théorie des incorporels dans l'ancien stoïcismede Émile Bréhier. 
13.

Las novedades de Tlön no terminan ahí : « Las naciones de ese planeta son -congénitamenteidealistas. Su lenguaje y las derivaciones de su lenguaje -la religión, las letras, la metafísicapresuponen el idealismo. El mundo para ellos no es un concurso de objetos en el espacio ; es una serie heterogénea de actos independientes. Es sucesivo, temporal, no espacial [...]. Todo estado mental es irreductible : el mero hecho de nombrarlo -

id est

, de clasificarlo- importa un falseo. De ello cabría deducir que no hay ciencias en Tlön -ni siquiera razonamientos. La paradójica verdad es que existen, en casi innumerable número » (435-436).

14. «El tema de "Tlön, Uqbar, Orbis Tertius" no es solo la postulación de unaidentidad entre libro y mundo. Es sobre todo la exaltación, entre eufórica y aterrada, del poder que tiene un libro -la enciclopedia- para producir otros mundos : para imaginarlos, engendrarlos e imponerlos sigilosamente en ese mundo que llamamos "nuestro". Borges socavó para siempre la inocencia, la

fe, la despreocupada credulidad con las que se visitaban la bibliotecas y se consultaban las enciclopedias, convirtiéndolas en Tienditas del Horror de la literatura » (Pauls 99).

15.

«That politics has always in some way been preoccupied with defending life doesn't detract from the fact that beginning from a certain moment that coincides exactly with the origins of modernity, such a self-defensive requirement was identified not only and simply as a given, but as both a problem and a strategic option. This means that all civilizations past and present faced and in some way met the needs of their own immunization, but that only in the modern ones does immunization constitute its core element. One might come to assert that it wasn't modernity that raised the question of the self-preservation of life, but that self-preservation raises itself in modernity's being [essere], which is to say it invents modernity as a historical and categorical apparatus that is capable of coping [risolvere] with it » (Esposito 52).

16.

Las mejores lecturas de Borges que se han producido en los últimos años son políticas (Ricardo Piglia, Beatriz Sarlo, Alan Pauls, Bruno Bosteels, Hernán Díaz). Yo confieso haber aprendido mucho de lo que sé de Borges con ellas. Creo, sin embargo, que previo a toda lectura política hay

que pensar el momento, en mi opinión central en su poética, antipolítico del pensamiento de Borges. La irresoluble tensión que su pensamiento propone entre las leyes del universo y las leyes de la polis.

Para los interesados en las lecturas políticas de Borges resulta muy recomendable la antología de Juan Pablo Dabove titulada

Jorge Luis Borges : Políticas de la literatura(2008).

17.

Pero no solo para Borges. Aristóteles definía el infinito en los siguientes términos : « El infinito ( ö́reipov

)... no es aquello fuera de lo cual no hay nada, sino aquello fuera de lo cual siempre hay algo »

(citado en

Breve historia del infinito

13). Y el acto civilizatorio primordial siempre involucra la capacidad de fundar fronteras, de crear límites definidos y estables. El

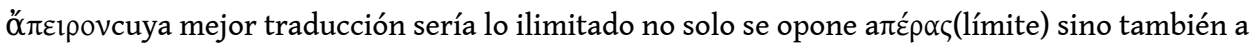
$\pi \varepsilon \tilde{\imath} \rho \alpha$

(conocimiento, experiencia). El infinito, entonces, no solo es imposible de delimitar sino que tampoco se puede pensar. El infinito, por ende, tiene un carácter negativo y potencial. Como aclara Paolo Zellini en el libro ya citado : « En el 
Tao te king

está escrito que "es gracias al constante alternarse del No-ser y del Ser como se verán de aquel el prodigio y de este los confines". Allá donde la realidad se halla conformada por el confín, el

verdadero infinito no puede, pues, manifestarse a no ser que contraído en la forma finita : para quienquiera que permanezca en el reino del Ser la transgresión del límite y la aspiración al prodigio se hallan siempre a punto de confundirse con la pura y simple disgregación de la forma » (17-18). A pesar de que es citada por Borges muchas veces, la otra gran tradición de pensar el infinito que lo define de un modo actual y positivo y cuya expresión mejor es la teoría de los números transfinitos de Cantor, me parece que tiene mucho menos influencia en su pensamiento. No se debe entender, sin embargo, de lo dicho que sea imposible una mediación entre la forma y lo ilimitado. Ya veremos más tarde que esa función mediadora la cumple en Borges lo sublime. En « Funes el memorioso » concibe Borges otra posible mediación entre lo inconmesurable y las formas. El cuento confirma el tópico clásico de que el infinito no puede ser pensado pero le agrega un matiz, en mi opinión, muy relevante : el infinito no puede ser pensado pero puede ser recordado.

18. Tomo el término « conmesura de imposibles » de Giorgio Agamben enEstancias por la belleza inherente a esta traducción de la definición de enigma en Aristóteles. Para una versión más fiel del texto aristotélico ver la traducción de Vicente García Yebra que dice : «Pues la esencia del enigma consiste en unir, diciendo cosas reales, términos inconciliables » ( Poética1458a).

19. VerLa sabiduría griegade Giorgio Colli (1998).

20.

No se debe olvidar que para Poe, la muerte de una mujer hermosa es, incuestionablemente, el tópico más poético del mundo, tal como lo dice en su « The Philosophy of Composition » (« the death, then, of a beautiful woman is, unquestionably, the most poetical topic in the world»). Esto adquiere mayor relevancia pues «El Aleph » es el cuento en donde Borges despliega con mayor claridad el hiato que existe entre la fuente de inspiración de un poema y su posterior composición.

21.

Para ver la importancia que tienen las dos acepciones de duelo, combate y funerario, en la obra de Borges ver « Saber dar muerte. El arte del duelo en Jorge Luis Borges».

22. Enrico Mario Santí en su libroCiphers of History propone una hipótesis que me parece no solo plausible sino muy fructífera : leer el Aleph como una parodia del

Canto general

de Pablo Neruda. Incluso llega a sugerir que D-A-N-E-R-I puede ser un anagrama por N-E-R-U-DA. Lo que resulta especialmente útil para mi lectura es la diferente forma de cantar « lo general » que proponen Neruda en su poema, Daneri en «La Tierra », y el Borges tanto ficticio como real cuando trata de narrar la revelación que recibió del Aleph.

23.

El mejor estudio sobre la repetición en este texto es el de Santiago Colá « Hopelessness and Potency : Borges' "El Aleph" ». Este artículo también constituye una interesante reflexión sobre la filosofía de la creación en Borges que, como indica el título, se alimenta tanto de la desesperación al tratar de reproducir el carácter infinito de esta revelación como de la potencia que demuestra a partir de su tono inspirado y casi místico cuando recrea la serie de visiones que el Aleph le otorgó como don, como regalo. 
24.

Recupero para mi lectura de este texto muchos de los aspectos que señala Alberto Giordano en su texto « Borges ensayista : avatares de la lectura » (1991). Baste la siguiente cita para destacar mi deuda con este texto : « Hay misterio cuando Borges no se contenta, no se tranquiliza con la explicación de los sinólogos, cuando siente

"algo más". Algo impreciso, tal vez innombrable, una emoción a la que le falta la palabra justa [...] Borges no busca [...] explicar el misterio, hacerlo desaparecer con una explicación. Busca preservarlo [...]. El ejercicio de una enunciación conjetural

-de la proliferación de adverbios (tal vez, quizá, acaso) es la huella más evidente -lo hace posible » $(1991: 18)$.

25. Esta postura de Borges tiene cierta afinidad con la que asume Deleuze enLógica del sentido , que se inspira en el texto de Emile Bréhier ya citado en este artículo y en la singular ontología que proponían los estoicos. Para Deleuze, el lenguaje es el lugar en donde subsisten las dos caras del sentido : la que delimita y nombra, la que crea un perfil definido para las cosas, pero también " la que sobrepasa los límites, y los restituye a la equivalencia infinita de un devenir ilimitado"

(2005 : 8). Este devenir ilimitado supone, en última instancia, la impugnación de la identidad personal y de la esfera del nombrar que le es inherente : los sustantivos y los adjetivos. Deleuze parece querer proponernos una filosofía de los verbos, del acontecer puro. Cómo cambiaría nuestra concepción del ejercicio filosófico si las categorías que tuviéramos que elucidar no fuera el ser o la nada, sino el verdear, o el oscurecer, devenires puros que viven más allá o más acá del concepto de sustancia y del concepto de Dios y de mundo, al menos como lo hemos entendido hasta ahora. La diferencia que tiene la posición de Borges respecto a esta es que Borges nunca llega a impugnar las formas, siempre intenta buscar una mediación entre estas y lo ilimitado, como se ha reiterado en este trabajo. 


\section{RESÚMENES}

«Creo en los razonables misterios, no en los milagros brutos », (124) afirmaba Borges en un texto titulado «Elementos de Preceptiva » que apareció en Sur

el 7 de abril de 1933. Este texto resume en pocas palabras lo que podría parecer, a primera vista, el eje de la filosofía de la creación en Borges : su apuesta por el orden en contra de la aventura, por el régimen de representación clásico que se opone al expresivo, por un género como el policiaco que privilegia el rigor de la estructura narrativa y la deducción racional que se contrapone a los excesos irracionales de la vanguardia, su apuesta, en fin, por una concepción más analítica y racional de la inspiración en contra de la clásica noción platónica que la concibe como un rapto, como un furor, como una manía. Pero, en una segunda mirada sobre el corpus borgiano, nos enfrentamos a dos problemas, si queremos defender la postura anterior y la noción de composición que le es inherente. El primero, es que en el corazón de su poética nos topamos con el más bruto de los milagros, con la más indomable de las aventuras del pensamiento. Aquel concepto que según el propio Borges : « es el corruptor y el desatinador de los otros. No hablo del

mal cuyo limitado imperio es la ética, hablo del infinito » (« Avatares de la tortuga », 254). El segundo problema tiene que ver con el protagonismo que tiene en la obra borgiana el concepto de revelación y la tensión que esto supone para una poética que quiere concebirse a sí misma en

los términos antes descritos. Al análisis de estos dos problemas y al giro que estos le dan a los conceptos de creación y composición en Borges estará dedicado este artículo.

« Je crois aux mystères raisonnables, pas aux miracles bruts » affirmait Borges dans un texte intitulé « Éléments de préceptive », paru dans la revue

Sur

, le 7 avril 1933. Ce texte résume en quelques mots ce qui pourrait sembler être, à première vue, l'axe de la philosophie de la création chez Borges : le choix de l'ordre plutôt que l'aventure, du régime de représentation classique qui s'oppose au régime expressif, d'un genre comme le roman policier, qui privilégie la rigueur de la structure narrative et la déduction rationnelle face aux excès irrationnels de l'avant-garde ; le choix, enfin, d'une conception plus analytique et rationnelle de l'inspiration, face à la notion classique de Platon, qui la conçoit comme un ravissement, une fureur, une manie. Mais, en regardant de plus près le corpus borgésien, nous sommes confrontés à deux problèmes si l'on veut défendre à la fois cette posture et la notion de composition qui lui est inhérente. Le premier réside dans le fait que, au cœur de sa poétique, on rencontre le plus brut des miracles, l'aventure la plus indomptable de la pensée. Ce concept qui, selon Borges lui-même, « corrompt et dérègle tous les autres. Je ne parle pas du Mal, dont l'empire est circonscrit à l'éthique ; je parle de l'infini » (« Avatars de la tortue », 254). Le deuxième problème relève de l'importance, dans l'œuvre de Borges, du concept de révélation, et de la tension qu'il suppose pour une poétique qui veut se penser dans les termes énoncés cidessus. Cet article est consacré à l'analyse de ces deux problèmes, et à la manière dont ils éclairent les concepts de création et de composition chez Borges. 
«I believe in reasonable mysteries and not in crude miracles » Borges affirmed in a text entitled «Elementos de preceptiva » that appeared in the journal

Sur

in 1933. This text summarizes, in a few words, what might appear upon first glance as the nucleus of Borges' philosophy of composition: his affirmation of order over adventure, for the classical notion of representation against the expressive one, for a genre such as the detective genre which privileges order and rational deduction against the irrational excesses of the avant-

garde. It presents a more analytical and rational conception of inspiration versus the classic platonic conception that sees inspiration as rapture, furor, and a mania. Upon a second reading of Borges' stories, we are confronted with two problems if we wish to defend the previously mentioned conception of inspiration and the conception of composition inherent to this notion.

The first problem is that at the heart of his poetics we are confronted with the most brute of miracles, with the most untamable adventures of thinking: infinity. It is a concept that according to Borges "is the corruptor and the remitter of others. I am not speaking of evil whose limited empire is ethics, I speak of the infinite " ("Avatares de la tortuga », 254). The second problem is about the protagonism of the concept of revelation in Borges' poetics as well as the tension that it presents in a poetics imbued with the notion of inspiration described above. This essay is an exploration of these two problems and the twist that these two problems present to the concepts of creation and composition in Borges.

ÍNDICE

Mots-clés: civiliser, l'infini, miracle, révélation, sublime

Palabras claves: civilizar, infinito, milagro, revelación, sublime

Keywords: civilize, infinite, miracle, revelation, sublime

\section{AUTOR}

JORGE BRIOSO

Carleton College 